\title{
Chapter 5 \\ Mesoscale Analysis of Flood Discharge and Energy Dissipation
}

\subsection{Background}

In a high-head dam project, due to the limitation of the storage capacity of the reservoir, it is necessary to discharge excess water downstream, which is the so-called "flood discharge." Some of today's mega-projects can have dam heights in excess of $300 \mathrm{~m}$, maximum flood discharge flow rates exceeding $50,000 \mathrm{~m}^{3} / \mathrm{s}$, flood discharge flow velocities over $50 \mathrm{~m} / \mathrm{s}$, and total flood discharge powers reaching 100,000 MW (Jia 2016). This large amount of kinetic energy can easily cause severe damage to the riverbed and structures behind the dam and even threaten the safety of the dam. Therefore, it is necessary to take appropriate measures so that the energy of the high-velocity flow is dissipated substantially in the discharge process, which is called "energy dissipation". In hydraulic and hydropower projects, the major forms of flood discharge and energy dissipation include ski-jump energy dissipation, underflow energy dissipation, and energy dissipation in a tunnel. From the perspective of energy dissipation, regardless of the form of flood discharge and energy dissipation, energy dissipation mainly results from the strong shear of water flow. The turbulent flow contains many vortex blobs of various sizes. Among them, the large vortex blobs obtain energy from the turbulent flow and transfer it by motion to small vortex blobs to drive the movement of the latter, which in turn further transfer the energy to smaller vortex blobs. This energy transfer continues until the very small vortex blobs dissipate the energy as heat in the process of overcoming the viscosity of water. This is known as the cascade mode of turbulent energy dissipation. Therefore, just like cavitation erosion, which is essentially a mesoscopic phenomenon, energy dissipation occurs on the mesoscale.

Traditionally, the main indicator for evaluating energy dissipation measures in an engineering project is the energy dissipation ratio, which is the ratio of the dissipated energy to the total energy before energy dissipation. An effective energy dissipation method must first have a high energy dissipation ratio. However, it is not sufficient to analyze and evaluate flood discharge and energy dissipation solely by macroscopic parameters such as the energy dissipation ratio (Wei-lin et al. 1996; 
Ohtsu et al. 1999). First, there are very large differences in the amounts of energy dissipated at different locations by water discharged at a high velocity from a reservoir. Hence, it is difficult to analyze this difference using macroscopic parameters, making it difficult to reasonably evaluate the effectiveness of energy dissipation measures. Second, energy dissipation and cavitation erosion prevention are conflicting objectives, as the former requires a change in the original flow state of the water, while the latter requires the minimization of the interference with the flow movement. In this context, we hope to determine not only the energy dissipation effect but also the risk of localized cavitation erosion damage.

A typical example in this regard is the Xiangjiaba Hydropower Station on the Jinsha River. A new form of energy dissipation called a "submerged jet", which is neither a ski-jump nor an underflow, is adopted for the dam of the station. The high-velocity water flow discharged from the surface and intermediate outlets of the dam body jets horizontally into the stilling basin in the middle of the water body between the water surface and the floor (Chen et al. 2010). To prevent the jets entering the stilling basin from rising to the surface of the water, leading to reduced energy dissipation performance, or diving to the bottom of the water, causing damage to the floor from the high-velocity water flow, the jets entering the stilling basin are divided into multiple jets at different heights that are independent of each other (Deng et al. 2008; Chen et al. 2014). This arrangement effectively guarantees the shear effect of the jets, but at the same time it forms transverse vortices between the jets and the floor, especially vertical vortices between different jet flows. If the vertical vortices penetrate the floor, it is possible for low pressure to be created at the floor but not cavitation erosion damage.

Clearly, only in-depth analysis of the small-scale vertical vortex structure under the horizontal jet condition can answer the question of whether cavitation erosion damage will occur. Moreover, for jet shear energy dissipation (including the vertical jet in the ski-jump energy dissipation method and the horizontal jet in the underflow energy dissipation method), it is necessary to understand the motion of vortex blobs in the shear zone and their energy dissipation effect to guide the development of engineering design solutions and operating methods. Pressure propagation in fissures also plays a decisive role even in the process of scouring and the failure of rock blocks or concrete floor blocks caused by high-head dam flood discharge. All of these flood discharge energy dissipation problems need to be analyzed on the mesoscale, such as the use of vortex blobs.

\subsection{Vortex Structure of a Single Jet}

Both main forms of flood discharge and energy dissipation, namely, the ski-jump and underflow energy dissipations, in high-head dam projects are classified as jet motion from the perspective of fluid motion (Fiorotto and Rinaldo 1992; Manso et al. 2007). The energy dissipation of the jet is first caused by the strong shear of the flow, then by the streamline curvature due to the collision with the solid boundary, and finally 
by the turbulent mixing of the flow (Ervine and Falvey 1987; Bollaert and Schleiss 2003). Among them, strong shear is the main cause of energy dissipation. Therefore, the study of the vortex structure during the jet shearing process is obviously very important.

\subsubsection{Velocity Field Characteristics of a Single Jet}

Figure 5.1 shows a schematic diagram of a single jet. Figure 5.2 shows the high-speed photographic visualization of jet flow patterns at different times. The cross section

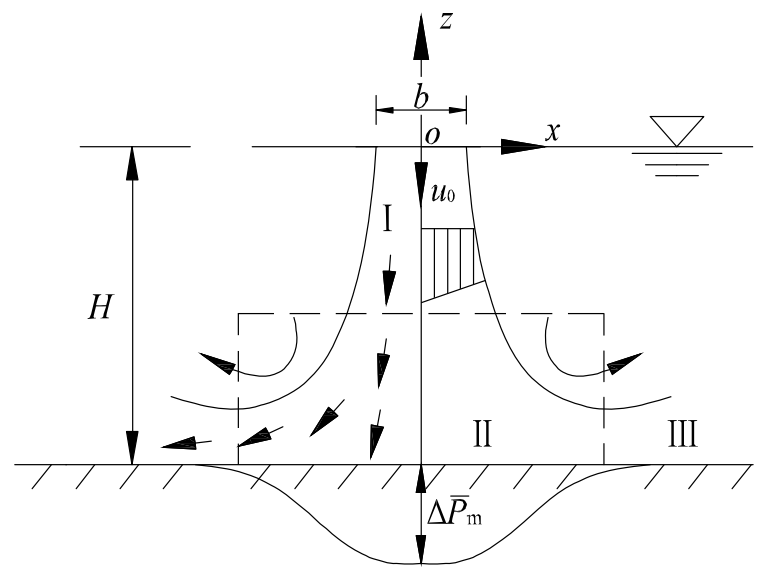

Fig. 5.1 Schematic diagram of a single jet

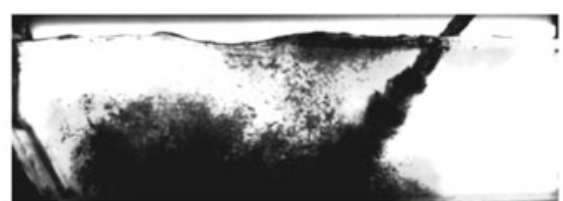

(a) $t=t_{0}+1.2 \mathrm{~s}$

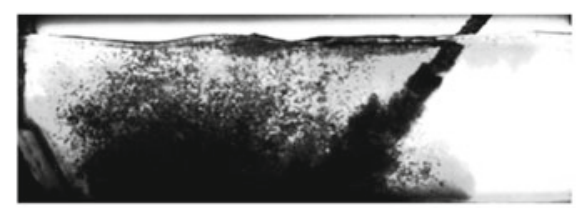

(c) $t=t_{0}+1.5 \mathrm{~s}$

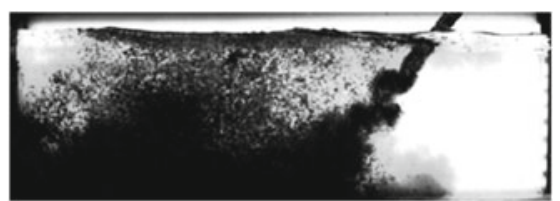

(b) $t=t_{0}+2.0 \mathrm{~s}$

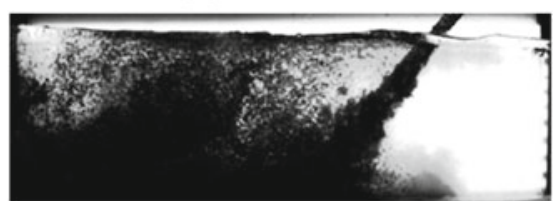

(d) $t=t_{0}+2.5 \mathrm{~s}$

Fig. 5.2 Flow patterns of a single jet 
of the jet exit is $2.0 \mathrm{~cm} \times 2.5 \mathrm{~cm}$, the exit velocity is $3.85 \mathrm{~m} / \mathrm{s}$, the exit angle is $\beta=$ $50^{\circ}$, and the downstream water depth is $20 \mathrm{~cm}$.

As seen, after the jet enters the downstream water, it shears the surrounding water and then impacts the floor. Finally, the jet moves along the floor and leaps. The movement of the jet in the downstream water can be divided into the shearing zone, impinging zone, and mixing zone.

The details of the jet movement can be clearly observed based on the particle image velocimetry (PIV) of the jet (Fig. 5.3) (Liu et al. 2015).

In the shearing zone, the incident flow shears with the surrounding water and drives it downward, resulting in instantaneous shear vortices of different sizes. The jet oscillates to some extent under the influence of the shear vortex motion. In the impinging zone, the jet impinges on the floor, which causes the streamline to bend sharply, resulting in a high impingement pressure. In the mixing zone, strong turbulent diffusion of the jet is present with numerous random vortices of different sizes.

\subsubsection{Vorticity Field Characteristics of a Single Jet}

According to turbulence theory, in addition to strong velocity pulsation, vortex motion exists in turbulence. That is, turbulence is composed of instantaneous vortices of different sizes, of which large vortices transfer energy while small vortices dissipate energy through shear and friction. At the places where violent vortex movement is present, intense energy transfer and dissipation is also present. The vortex strength of a turbulent flow is expressed by the vorticity. Figure 5.4 shows the time-averaged vorticity field of a jet. The jet edge in the shearing zone continuously entrains the surrounding water, and the vorticity field is characterized by a high strength and a concentrated range, while the vorticity field in the mixing zone has the characteristics of a weak strength but a large range.

The vortices formed by the shearing between the jet and the surrounding water are clockwise upstream of the jet and counterclockwise downstream. The size and position of the vorticity change constantly along the course, with remarkable instantaneous and random characteristics.

On the jet axis, the absolute value of the vorticity is approximately 0 , while from the jet axis to the boundary on both sides of the jet, the absolute value of the vorticity first increases and then decreases. This indicates that the relatively large velocity gradient between the jet and the surrounding water causes the turbulent vortices to rotate at a high velocity, generating a relatively high vorticity. The greater the velocity gradient between the jet and the surrounding fluid, the greater the ability of the jet to drive the motion of the surrounding fluid is, and the larger the vorticity value is. Along the jet flow, due to the constant motion of the vortices, the jet flow velocity keeps decreasing, and the velocity gradient between the jet and the surrounding fluid decreases, so the vorticity value keeps decreasing. In the mixing zone far away from the jet, the vorticity value decreases significantly and is evenly distributed. Therefore, shear is the main cause of jet energy dissipation unless the water is very shallow. 


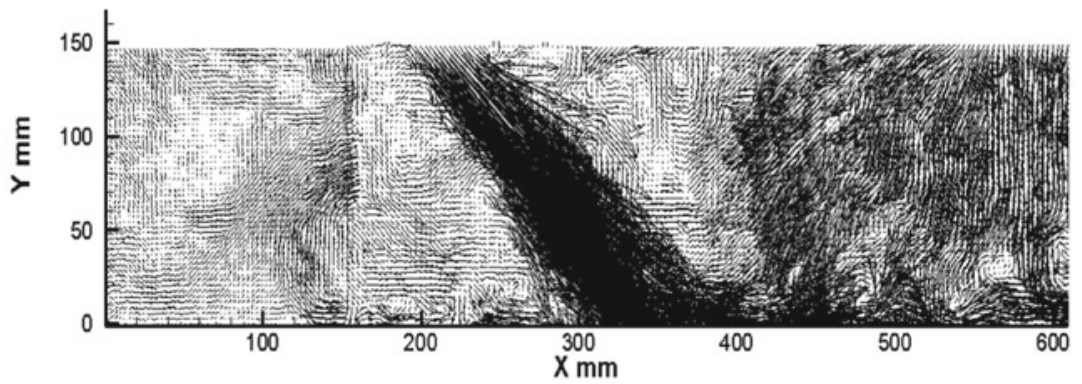

(1) $\mathrm{t}=1.031 \mathrm{~s}$

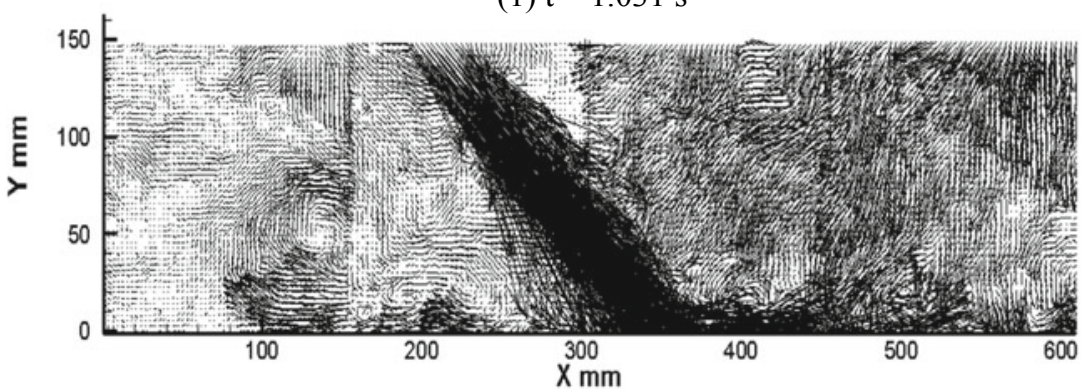

(2) $t=2.062 s$

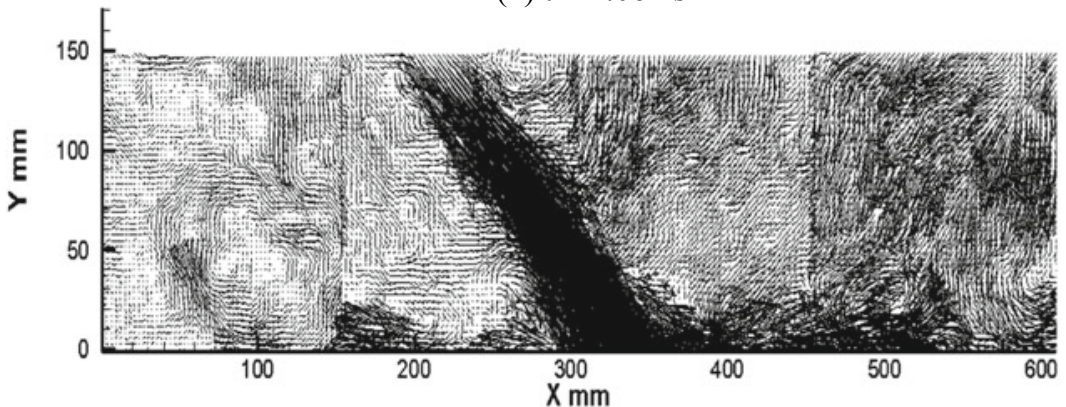

(3) $t=3.093 \mathrm{~s}$

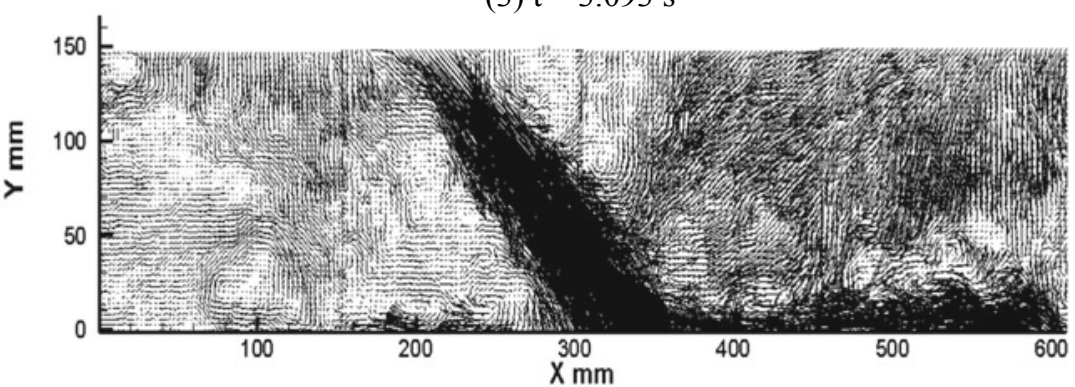

(4) $t=4.124 \mathrm{~s}$

Fig. 5.3 Instantaneous vector diagrams of the oblique jet incident to an axial streamwise section 


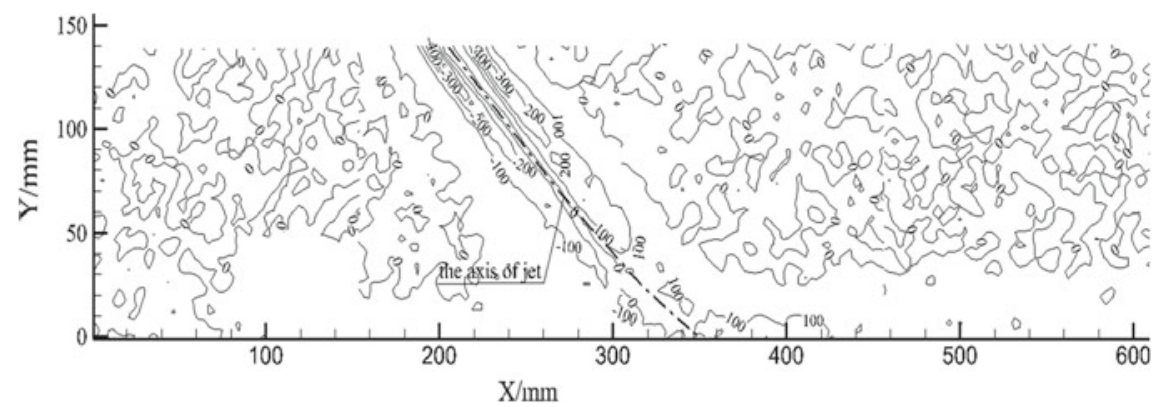

Fig. 5.4 Average vorticity field of a jet

The large-eddy simulation (LES) technique was used to numerically simulate vortices of all scales in the turbulent flow. Figure 5.5 shows the map of the vorticity evolution in the shearing zone (Guo et al. 2017). To help determine the relationship between the pressure and vorticity, the pressure contour map is superimposed on the original vorticity map. The red "+" and the black "-" marks denote high pressure and low pressure at the centers of the circular regions, respectively.

When the jet first enters the water, the shear motion on both sides of the jet is the strongest, and the vorticity reaches its maximum. The velocity gradient first increases and then decreases from the jet axis to the outer edge of the jet. Therefore, the vorticity first increases and then decreases from the jet axis to each side of the jet. In the shearing zone, both vorticity beams are relatively regular, being large in the middle and small at both ends and exhibiting a lotus-root-shaped distribution. After entering the impinging zone, the jet diverts under the influence of the wall surface, causing the velocity gradient to change significantly, so the vorticity beams begin to differentiate.

With the continuous transport of the jet kinetic energy, the vortices generated by the shearing between the jet and the surrounding water move downstream along with the jet, corresponding to the high-vorticity region moving downstream in the figure. As seen in the figure, the two vorticity beams simultaneously oscillate to the right at time $\mathrm{t}$ and, after $0.02 \mathrm{~s}$, simultaneously oscillate to the left and then return to their original positions. As the jet continues, the two vorticity beams oscillate in opposite directions and then gradually return to their original positions, ready for the next round of oscillation. The oscillation of the vorticity beams is consistent with the random oscillation of the jet observed in the experiment, indicating that the random oscillation of the jet mainly results from vortex oscillation.

A comparison of the vorticity and pressure distributions shows that high-vorticity regions are usually of oblate shape, corresponding to low pressures at the centers of the circular regions, and the low-vorticity regions at the two ends of the oblate regions correspond to high pressure at the centers of the circular regions, indicating that the presence of high vortices results in low pressure at the centers of the circular regions. Taking the lower side of the jet as an example, the shearing between the jet and the downstream water continuously produces counterclockwise vortices. As 
vorticity-mag: $\quad 0 \quad 200300400500600700800900100011001200$

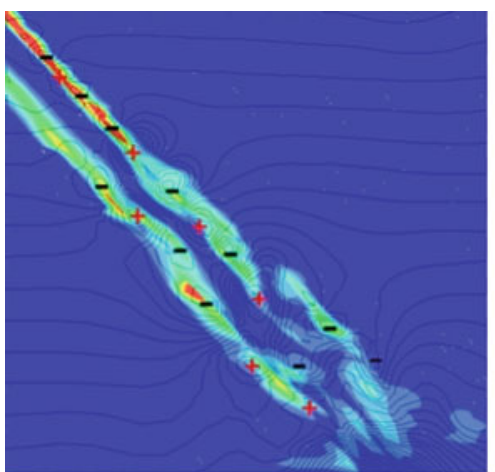

(a) $\mathrm{t}+0.00$

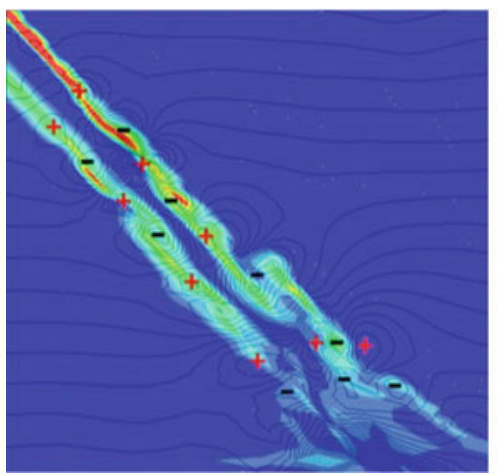

(c) $\mathrm{t}+0.04$

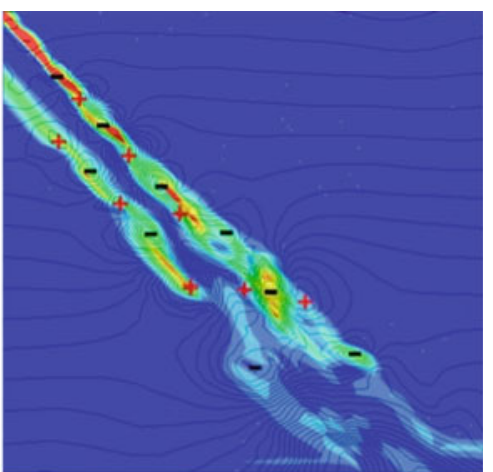

(b) $\mathrm{t}+0.02$

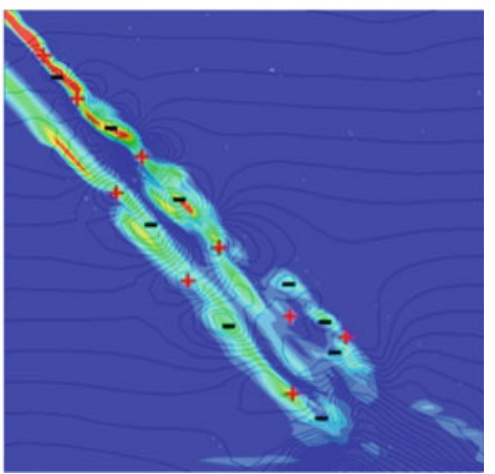

(d) $\mathrm{t}+0.06$

Fig. 5.5 Vorticity distribution and evolution (unit: $\mathrm{s}^{-1}$ )

the vortices move downstream along with the jet, low pressure is generated at the centers of the circular regions where vortices exist, and high pressure at is generated the centers of the circular regions due to the squeezing of the fluid by the two vortices in front of and behind it. This explains the alternating distribution of low pressure and high pressure at the centers of the circular regions.

\subsection{Vortex Structure with Multijets}

Multijets usually appear in high-head dam projects (Saripalli 1987; Barata et al. 1991). From the perspective of the vortex structure, the relatively complex multijets, the so-called multihorizontal submerged jets, enter the downstream water from the horizontal direction at a certain height between the water surface and the floor. 
The complexity of the multihorizontal submerged jets is mainly reflected by the simultaneous existence and mutual interference of transverse vortices and transverse vortices (Chen et al. 2013). In particular, if the vertical vortices penetrate the floor, they may generate low pressure at the floor and induce cavitation erosion.

\subsubsection{Transverse Vortices}

Figure 5.6 shows the layout of the test model, for which particle image velocimetry (PIV) was used to measure the flow field. In the model, the water flows through the surface and intermediate outlets of the dam and enters the stilling basin at two levels in the form of multijets.

Figure 5.7 is the streamline diagram of the transverse vortices in the streamwise section near the sidewall of the stilling basin for the multilevel multihorizontal submerged jets. The merging and breakdown of the transverse vortices can be clearly seen in the figure. At time $T=\left(t_{0}+0\right) \mathrm{s}$, a vortex with a size of approximately $16 \mathrm{~m}$ $\times 10 \mathrm{~m}$ appeared in the turbulent shear layer near the sidewall of the stilling basin. This vortex disappeared at $T=\left(t_{0}+1\right) \mathrm{s}$. At $T=\left(t_{0}+2.5\right) \mathrm{s}$, two vortices of different sizes occurred in the turbulent shear layer. At $T=\left(t_{0}+3\right) \mathrm{s}$, the two vortices merged into one. The vortices continued to form and disappear with increasing time. Due to the complex boundary conditions and violent turbulent flow in the stilling basin, the interaction between the vortices was very strong, and the vortex structure was very irregular. When large-size vortices occurred in the turbulent shear layer, they soon broke down to form smaller vortex structures. The vortices in the turbulent shear layer experienced a continuous process of formation-merging-breakdown-disappearance. The position of a transverse vortex was not fixed at a certain location but constantly changed within a range of $0-50 \mathrm{~m}$ from the step-down floor. Additionally, the distance from the center of the vortex to the floor of the stilling basin changed constantly.
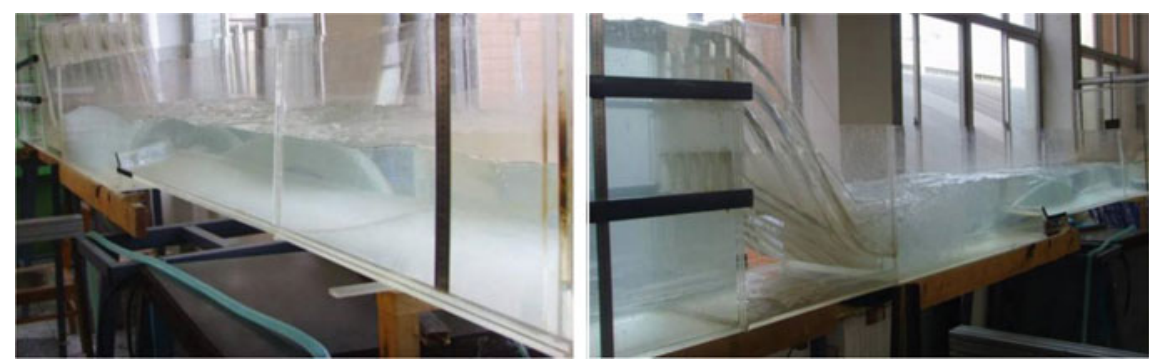

Fig. 5.6 Layout of the test model 

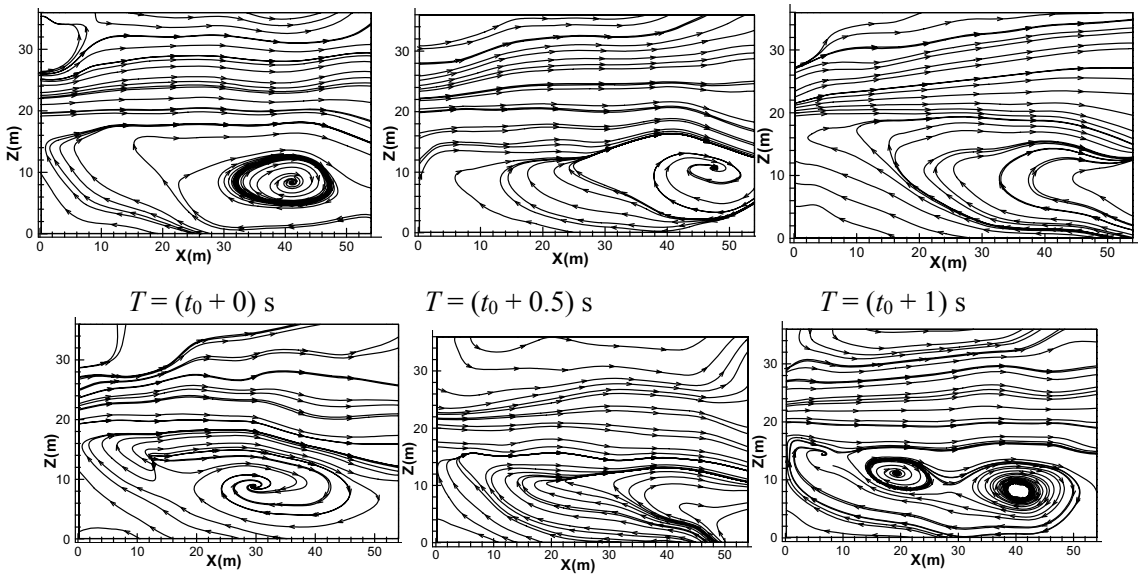

$T=\left(t_{0}+0.5\right) \mathrm{s}$

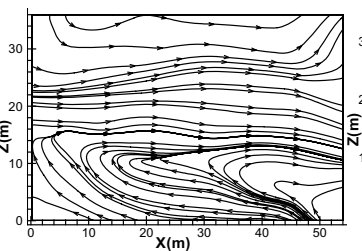

$T=\left(t_{0}+1\right) \mathrm{s}$

$T=\left(t_{0}+1.5\right) \mathrm{s}$

$T=\left(t_{0}+2\right) \mathrm{s}$
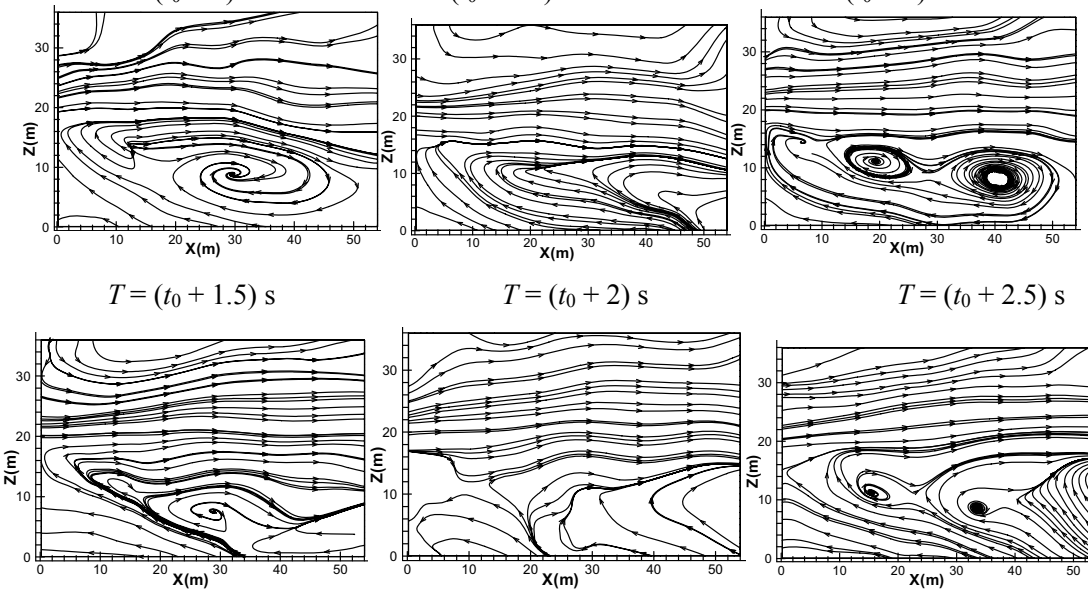

$T=\left(t_{0}+2.5\right) \mathrm{s}$

$T=\left(t_{0}+3\right) \mathrm{s}$

$T=\left(t_{0}+3.5\right) \mathrm{s}$
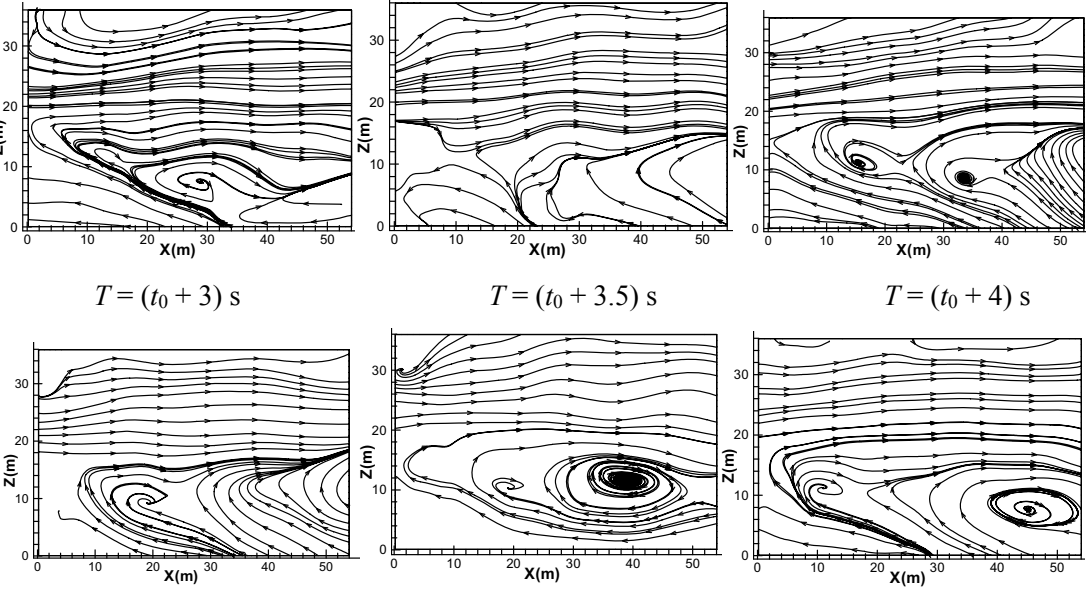

$T=\left(t_{0}+4\right) \mathrm{s}$

$T=\left(t_{0}+4.5\right) \mathrm{s}$

$T=\left(t_{0}+5\right) \mathrm{s}$

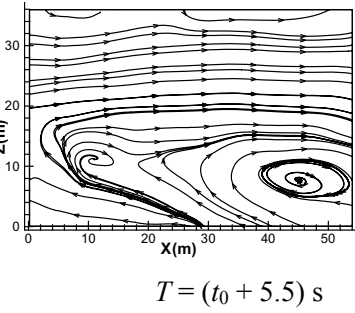

Fig. 5.7 Streamline diagram of transverse vortex motion (streamwise section near sidewall)

\subsubsection{Vertical Vortices}

Figure 5.8 shows the distribution and streamline diagram of the vertical vortices in the horizontal section $1 \mathrm{~cm}$ away from the floor. As seen from the figure, there was an obvious vortex blob structure in the flow field most of the time near the floor of the stilling basin, indicating that the vertical vortices generated in the stilling basin were intermittent underflow. The range of the vertical vortices near the floor of the stilling basin was smaller than $4 \mathrm{~cm} \times 4 \mathrm{~cm}$, and the position of a vertical vortex was not fixed at a certain location but changed constantly. As seen from the streamline distribution diagram at different moments in time, the vertical vortices near the step-down floor 

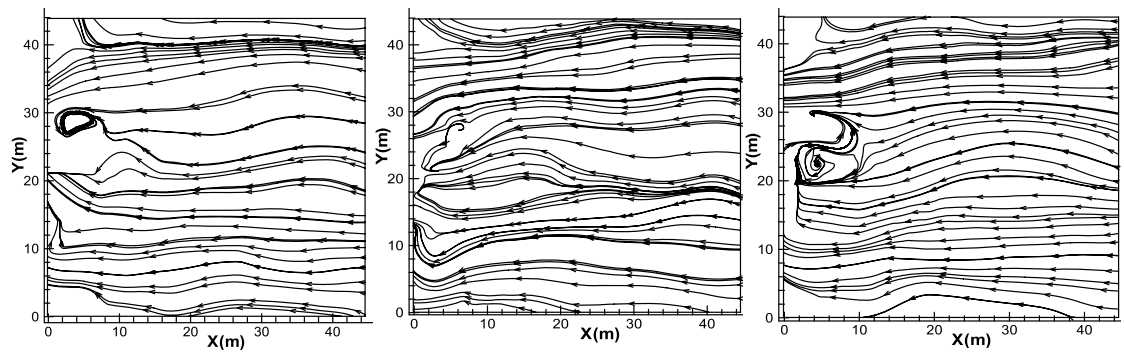

$$
T=\left(t_{0}+0\right) \mathrm{s}
$$

$$
T=\left(t_{0}+0.5\right) \mathrm{s}
$$
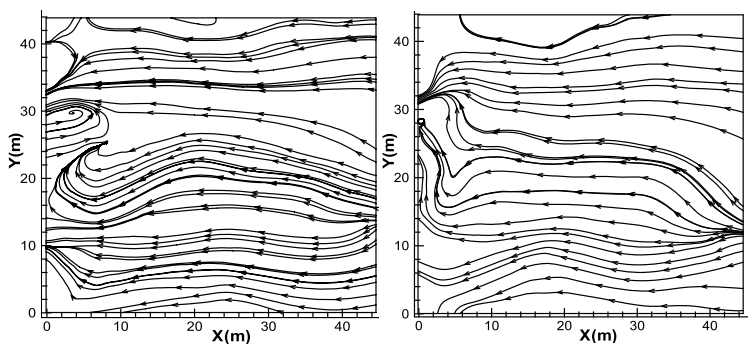

$$
T=\left(t_{0}+1\right) \mathrm{s}
$$

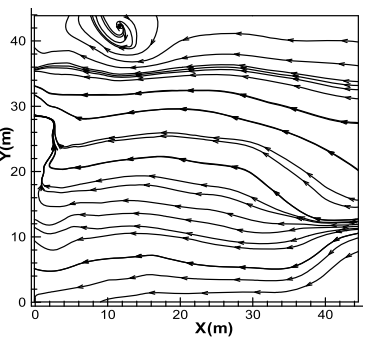

$$
T=\left(t_{0}+1.5\right) \mathrm{s}
$$

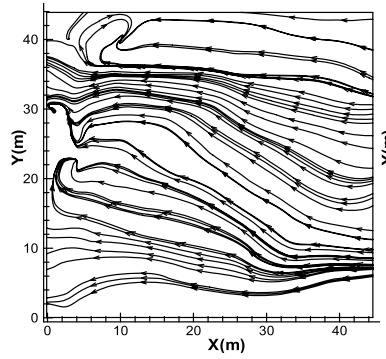

$$
T=\left(t_{0}+2\right) \mathrm{s}
$$

$$
T=\left(t_{0}+2.5\right) \mathrm{s}
$$
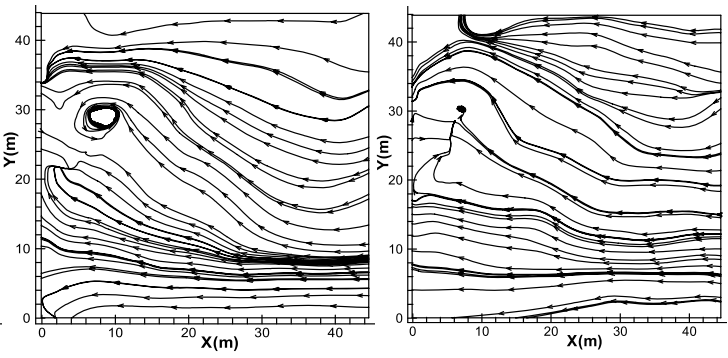

$$
T=\left(t_{0}+3\right) \mathrm{s}
$$

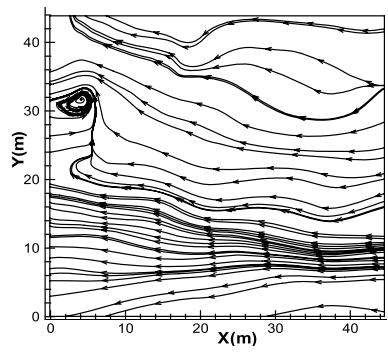

$$
T=\left(t_{0}+3.5\right) \mathrm{s}
$$

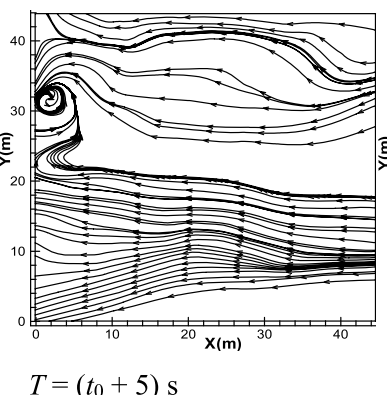

$$
T=\left(t_{0}+4\right) \mathrm{s}
$$

$$
T=\left(t_{0}+4.5\right) \mathrm{s}
$$

$$
T=\left(t_{0}+5\right) \mathrm{s}
$$

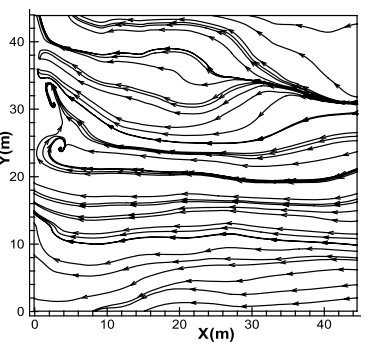

$T=\left(t_{0}+5.5\right) \mathrm{s}$

Fig. 5.8 Streamline diagram of the vertical vortex motion (horizontal section near floor) 

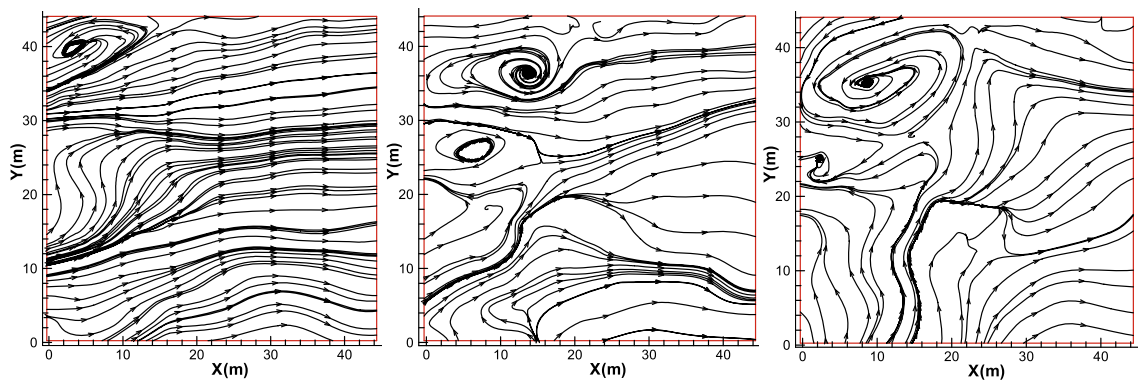

$Z=18 \mathrm{~cm}$

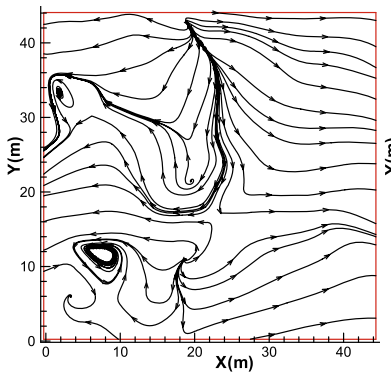

$Z=5 \mathrm{~cm}$

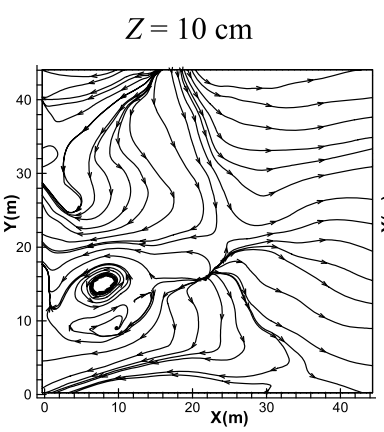

$Z=3 \mathrm{~cm}$
$Z=7 \mathrm{~cm}$

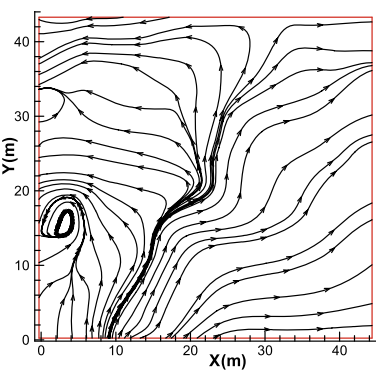

$Z=1 \mathrm{~cm}$

Fig. 5.9 Vertical transfer of vertical vortices

constantly formed and disappeared, and vertical vortices continued to appear, some disappearing immediately after generation and others lasting for a short time. Thus, the vertical vortices occurred intermittently near the floor of the stilling basin, and the vertical vortices did not appear at a fixed position on the floor of the stilling basin. The transverse vortices played a role in enhancing the randomness of the vertical vortices.

Figure 5.9 shows the formation and vertical transfer of the vertical vortices in the stilling basin, where $\mathrm{Z}$ is the distance from the test plane to the floor of the stilling basin. As shown in the figure, there was violent turbulence in the flow in the stilling basin, and vertical vortices constantly formed and disappeared in the vertical direction. The vertical vortex formed between the high-velocity jets was transferred toward the floor of the stilling basin, and the vortex area first increased and then gradually decreased and finally disappeared in the water of the stilling basin. The vertical vortex formed in the water below the high-velocity mainstream continuously developed downward and ultimately reached the floor of the stilling basin with a vortex area of approximately $4 \mathrm{~cm} \times 4 \mathrm{~cm}$.

The above analysis shows that under the interference of the turbulence of the jets themselves and the transverse vortices, although the vertical vortex formed by the multihorizontal jets could intermittently reach the floor of the stilling basin, there was no continuously penetrating vertical vortex, so the floor of the stilling basin was not damaged by cavitation erosion. 


\title{
5.4 Vortex Structure of a Pressure Flow with a Sudden Contraction
}

In high-head dam projects, in addition to the traditionally used ski-jump and underflow energy dissipation methods, the so-called internal flow energy dissipation method, with which energy is dissipated in spillway tunnels, has been increasingly adopted in engineering projects over the past two decades (Chen et al. 2007; Zhong et al. 2009; Wu and Ai 2010). Sudden contraction is a typical internal flow energy dissipation method for the pressure flow in spillway tunnel. In this section, the LES method is used to analyze the vortex structure of a pressure flow with a sudden contraction.

\subsubsection{Flow Field Characteristics of a Pressure Flow with a Sudden Contraction}

Figure 5.10a shows the instantaneous velocity contour plot and streamlines of a pressure flow with a sudden contraction. The fluid boundary layer is separated at the front edge of the sudden contraction, forming a recirculation zone near the wall (Durrett et al. 1988; Tamura and Matsumoto 2009; Roul and Dash 2011). There is a mixed layer at the junction of the recirculation zone and the mainstream that has properties similar to those of the boundary layer, with relatively large shear stress and strong turbulence. Under the shear of the mixed layer, vortex blobs were formed in the recirculation zone, and the pressure at the center of the vortex blob decreased, making cavitation possible. In the figure, the streamlines are actually three-dimensional, and the intersecting of the streamlines is an optical illusion due to the viewing angles. Figure $5.10 \mathrm{~b}$, c shows the contour plots of the corresponding time-average and root-mean-square (RMS) values of the flow velocity, respectively.

\subsubsection{Vortex Blob Characteristics of a Pressure Flow with a Sudden Contraction}

\begin{abstract}
According to turbulence theory, large vortices draw energy from the mainstream and transfer it in layers to small vortices, which eventually convert the kinetic energy into heat through viscous dissipation. The form of the large vortices mainly depends on the shape of the boundary. In a pressure flow with a sudden contraction, the boundary layer at the front edge of the sudden contraction is separated, and a large number of vortex blobs are generated in the low-pressure region formed by the separation, playing a decisive role in the cavitation inception. Next, the form and distribution of these vortex blobs are investigated.
\end{abstract}



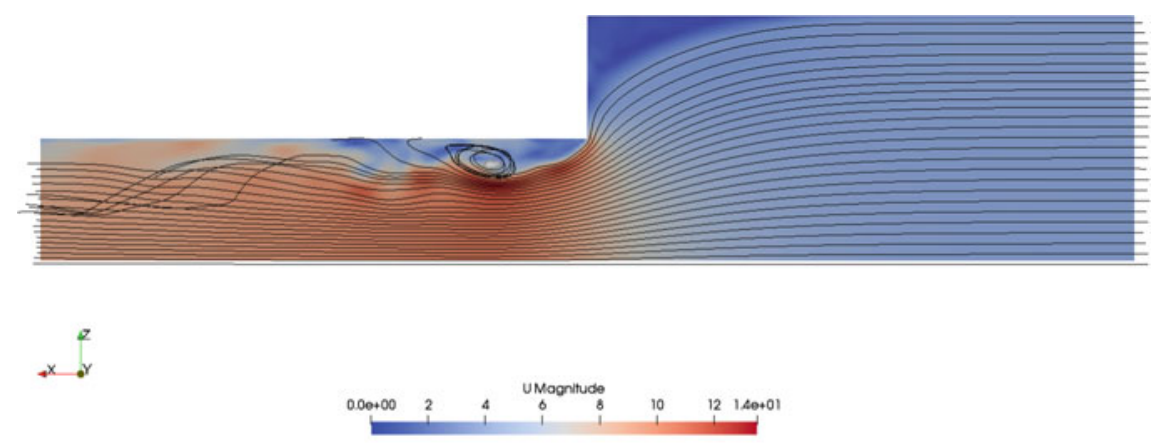

a) Contour plot and streamlines of the instantaneous flow velocity
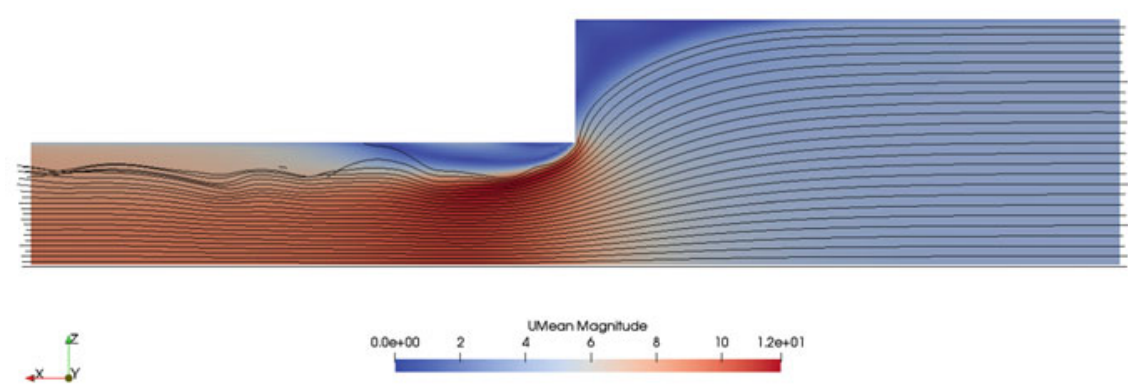

b) Contour plot and streamlines of the time-averaged flow velocity
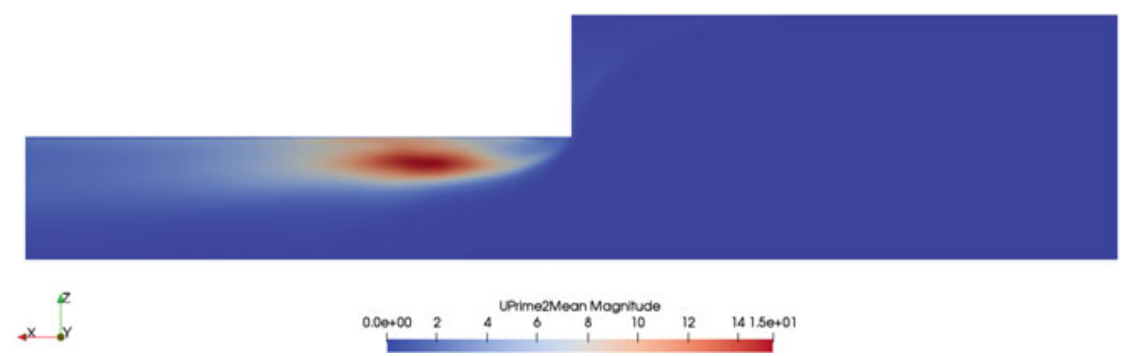

c) Contour plot of the RMS of the flow velocity

Fig. 5.10 Contour plots of the instantaneous, time-averaged, RMS flow velocities

The $\mathrm{Q}$ criterion and $\lambda_{2}$ criterion are common indicators for identifying vortex blobs. The core idea of the $\mathrm{Q}$ criterion is to define the region where the vorticity is greater than the strain rate as a vortex. $\lambda_{2}$ is the second characteristic value of the sum of the squares of the strain rate tensor and the vorticity tensor. They are calculated as follows: 
The gradient tensor of the flow velocity field is defined as

$$
\mathbf{J}=\nabla \mathbf{u}=\left[\begin{array}{lll}
\frac{\partial u_{1}}{\partial x} & \frac{\partial u_{2}}{\partial x} & \frac{\partial u_{3}}{\partial x} \\
\frac{\partial u_{1}}{\partial y} & \frac{\partial u_{2}}{\partial y} & \frac{\partial u_{3}}{\partial y} \\
\frac{\partial u_{1}}{\partial z} & \frac{\partial u_{2}}{\partial z} & \frac{\partial u_{3}}{\partial z}
\end{array}\right]
$$

Then, its symmetric component is the strain rate tensor

$$
\mathrm{S}=\frac{\mathrm{J}+\mathrm{J}^{\mathrm{T}}}{2}
$$

and its antisymmetric component is the vorticity tensor

$$
\Omega=\frac{\mathrm{J}-\mathrm{J}^{\mathrm{T}}}{2}
$$

The $Q$ value is defined as

$$
\mathrm{Q}=\frac{1}{2}\left(\left\|\Omega^{2}\right\|-\left\|S^{2}\right\|\right)
$$

The position where $\mathrm{Q}$ is greater than zero is a vortex. In practice, this criterion is too weak, and hence, too many vortices would be obtained, adversely affecting the analysis. Therefore, the $\mathrm{Q}$ value is generally set to be greater than simply a positive number.

The $\lambda_{2}$ criterion requires the determination of the three eigenvalues $\left(\lambda_{1}, \lambda_{2}\right.$, and $\left.\lambda_{3}\right)$ of $S^{2}+\Omega^{2}$. For a point in the flow field to be the center of a vortex, two of the three eigenvalues must be less than 0 . We know that $\lambda_{1}>\lambda_{2}>\lambda_{3}$; thus, $\lambda_{2}<0$ is a necessary condition. In practical applications, this criterion is weak and would lead to a large number of vortices. Therefore, $\lambda_{2}$ is generally set to be less than simply a negative number to obtain the vortex structure. The disadvantage of this method is that it is difficult to distinguish several vortex blobs at relatively close distances. Note that the value calculated for Lambda2 in OpenFOAM is the opposite of the aforementioned $\lambda_{2}$, and the original definition of $\lambda_{2}$ is adopted here.

Figure 5.11 shows that the identification results with the two criteria are almost the same. In principle, the $\lambda_{2}$ criterion is better and thus is used in the following analysis.

To illustrate the motion of the vortex blob at different flow velocities, the vortex blob downstream of the sudden contraction as the inlet flow velocity increased from 2 to $8 \mathrm{~m} / \mathrm{s}$ is shown in Fig. 5.12. The higher the flow velocity was, the more and larger the vortices were in the flow field.

According to the mesoscopic analysis of the vortex blob structure of a pressure flow with a sudden contraction, there was a high risk of cavitation in the vortex zone after the sudden contraction (Arndt et al. 1995; Chen et al. 2009). Therefore, a decompression model test is necessary to evaluate the risk of cavitation when designing 


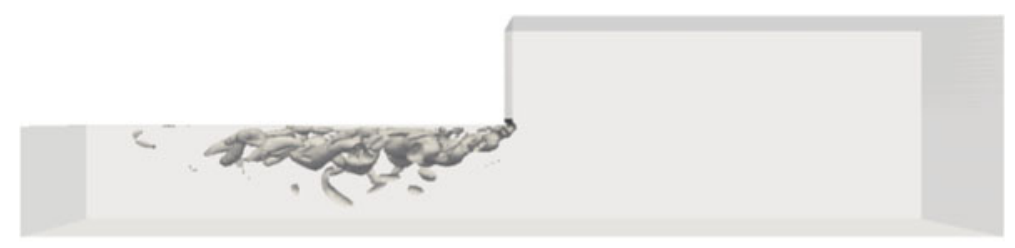

(a) Contour surface $Q=100000$

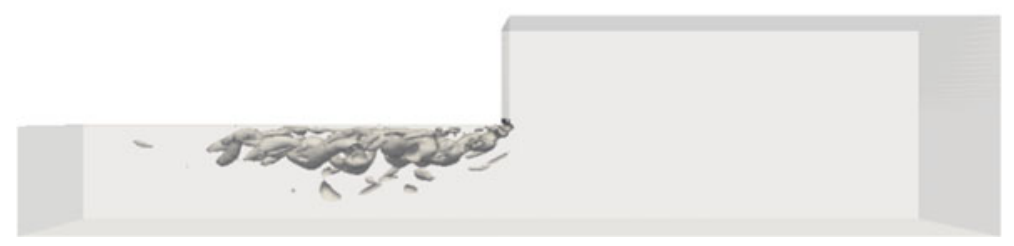

(b) Contour surface $\lambda_{2}=-50000$

Fig. 5.11 Comparison of the identification results by criteria $Q$ and $\lambda_{2}$

energy dissipation facilities with a sudden contraction in engineering projects. Unlike orifice plate structures, structures with sudden contractions make it difficult to ensure that the cavitation bubbles do not collapse near the sidewall after their formation. In addition, unlike in nonpressure flow, it is impossible to use a bucket-chute in a pressure flow to achieve forced aeration for cavitation reduction because a large amount of air would accumulate in the tunnel and form high-pressure air pockets, which would adversely affect the structural safety. Therefore, when cavitation occurs, air vents, as shown in Fig. 5.13, can be used to reduce the cavitation erosion damage. Figure 5.14 shows the distribution of the air concentration formed by aeration with an air vent. Even if the air vent is not close to the front edge of the sudden contraction and there is only one air vent in the contraction section, the entrained air bubbles can still counterdiffuse in the flow direction to reach the front edge of the contraction and spread across the entire width in the transverse direction. This occurs because these are all low-pressure regions, which attract the air bubbles moving toward them (Li et al. 2019).

\subsection{Application of Multihorizontal Submerged Jets in Engineering Project}

\subsubsection{Overview of the Project}

The Xiangjiaba Hydropower Station is the last in the cascade development of the lower reaches of the Jinsha River. The dam is located on the lower reaches of the 


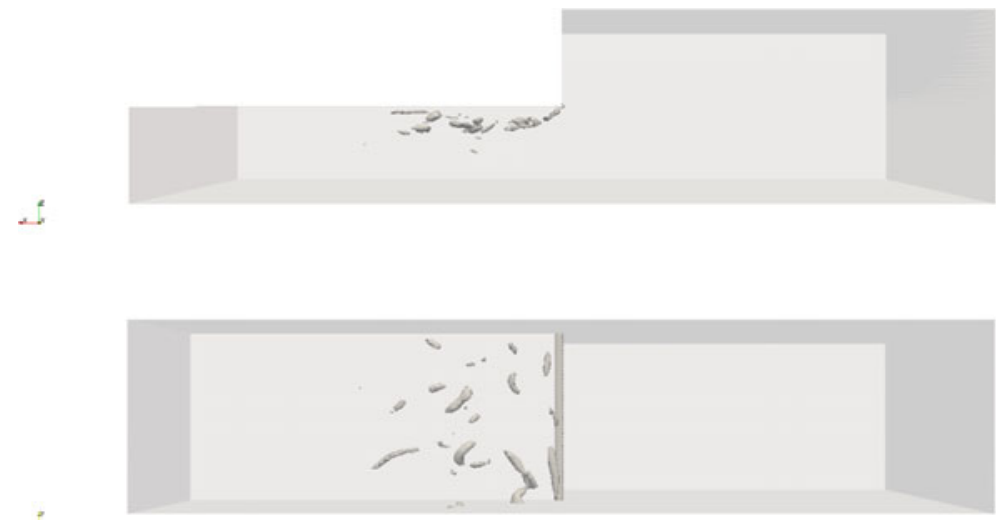

(a) Inlet flow velocity $=2 \mathrm{~m} / \mathrm{s}$
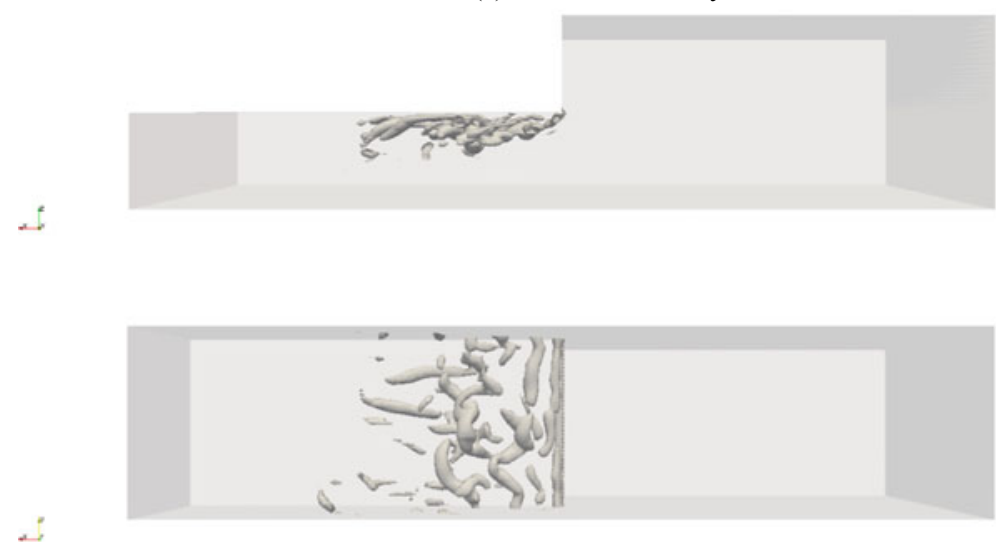

(b) Inlet flow velocity $=3 \mathrm{~m} / \mathrm{s}$
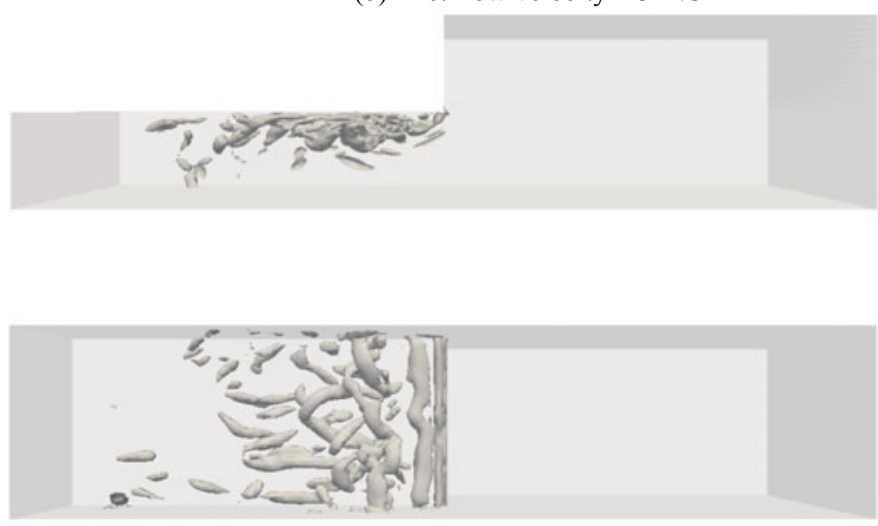

(c) Inlet flow velocity $=4 \mathrm{~m} / \mathrm{s}$

Fig. 5.12 Vortex blob at different flow velocities (contour surface $\lambda_{2}=-50000$ ) 

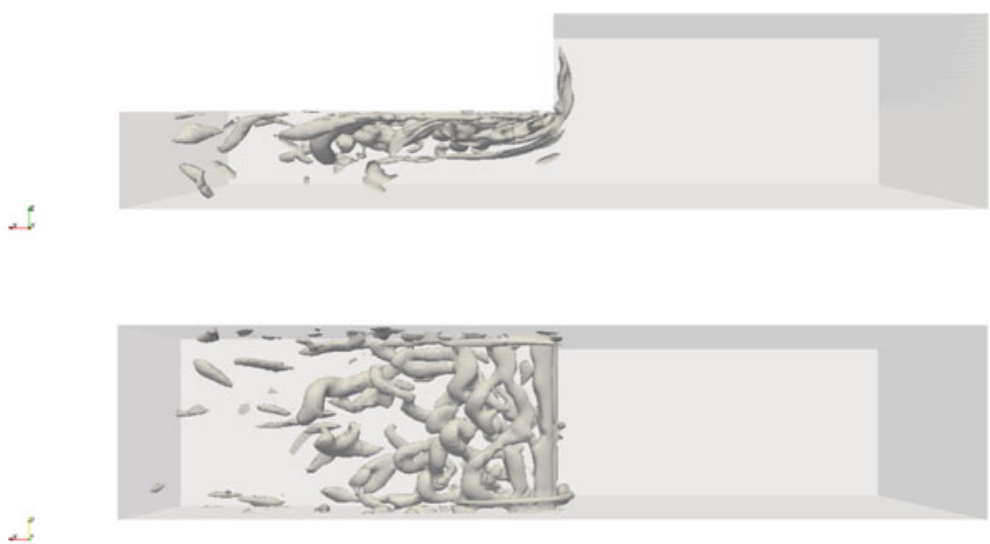

(d) Inlet flow velocity $=6 \mathrm{~m} / \mathrm{s}$
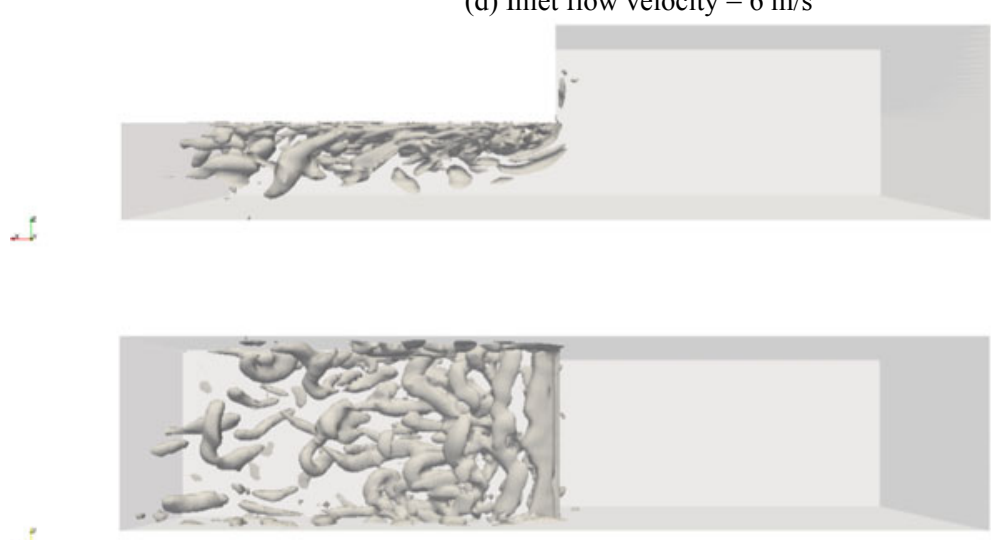

(e) Inlet flow velocity $=8 \mathrm{~m} / \mathrm{s}$

Fig. 5.12 (continued)

Jinsha River at the junction of Shuifu County in Yunnan Province (right bank) and Yibin County in Sichuan Province (left bank). Xiangjiaba is $157 \mathrm{~km}$ upstream away from the Xiluodu Hydropower Station, $1.5 \mathrm{~km}$ downstream away from the downtown Shuifu and $33 \mathrm{~km}$ upstream away from downtown Yibin. Xiangjiaba is a gravity dam with a crest elevation of $383 \mathrm{~m}$, a maximum height of $161 \mathrm{~m}$, and a crest length of $909.3 \mathrm{~m}$. It has a normal storage water level of $380 \mathrm{~m}$, check flood level of $381.86 \mathrm{~m}$, dead water level (drawdown water level when power is not generated during the water supply period) and flood control water level during flood season of $370 \mathrm{~m}$, upstream highest navigable water level of $380 \mathrm{~m}$, downstream highest navigable water level of $278 \mathrm{~m}$, maximum navigable flow rate of $12,000 \mathrm{~m}^{3} / \mathrm{s}$, and minimum navigable flow rate of $1200 \mathrm{~m}^{3} / \mathrm{s}$. The reservoir covers an area of $95.6 \mathrm{~km}^{2}$ and is of a canyon type. The reservoir has a control drainage area of $458,800 \mathrm{~km}^{2}$, a total capacity of 5.163 billion $\mathrm{m}^{3}$, and a backwater length of $156.6 \mathrm{~km}$. With an installed capacity 


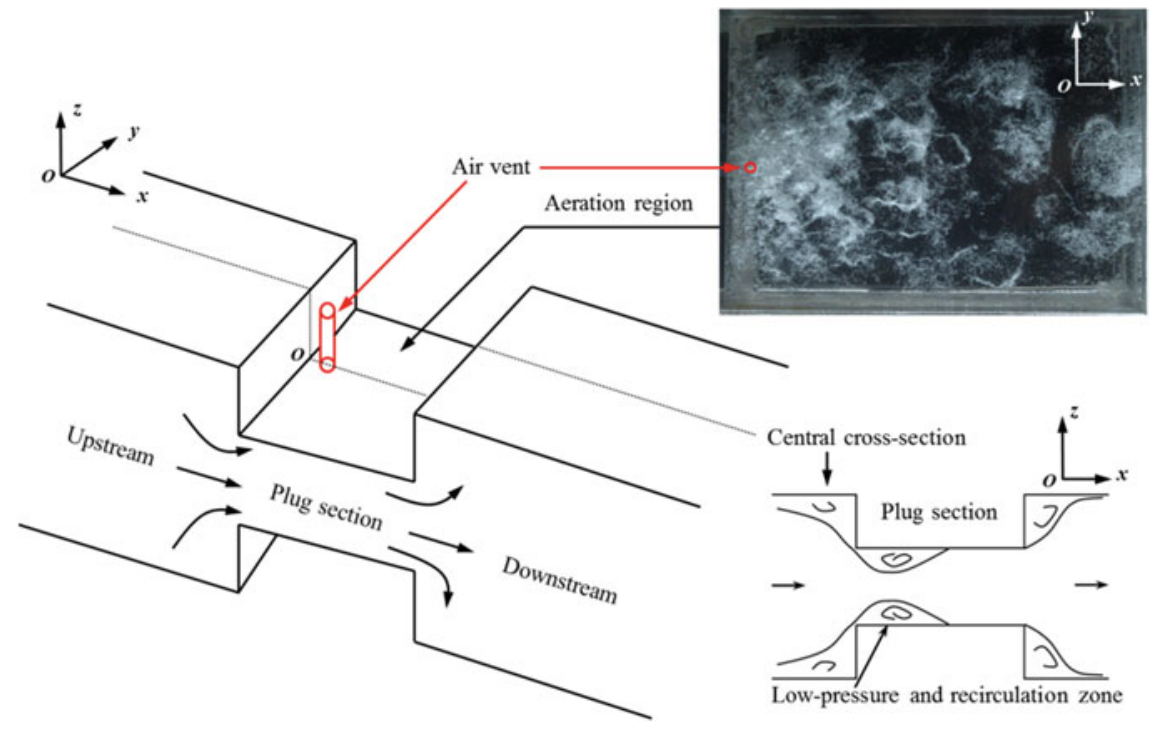

Fig. 5.13 Aeration for erosion reduction by air vents in pressure flow with sudden contraction

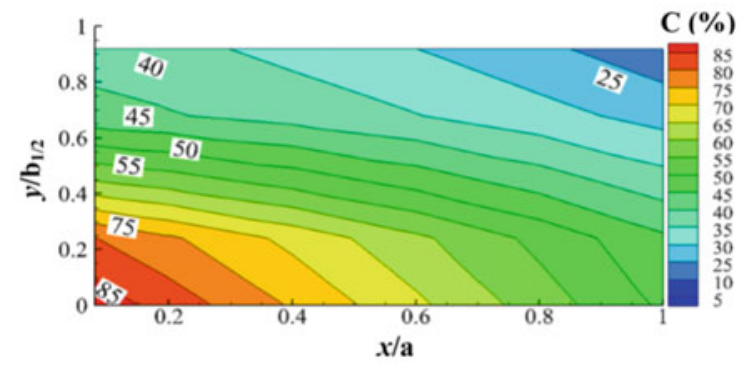

(a) Air replenishment $Q_{\mathrm{a}}=1.67 \mathrm{~m}^{3} / \mathrm{s}$

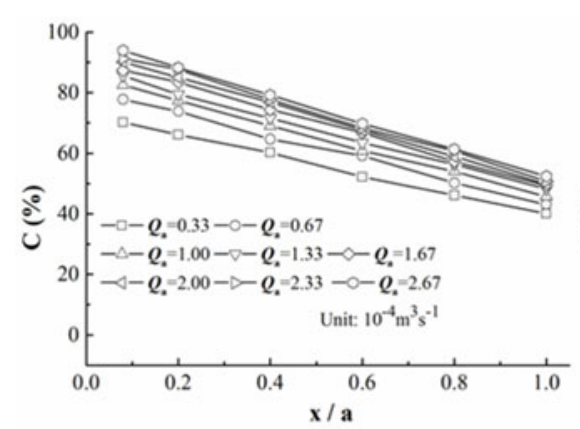

(b) $y / b_{1 / 2}=0$

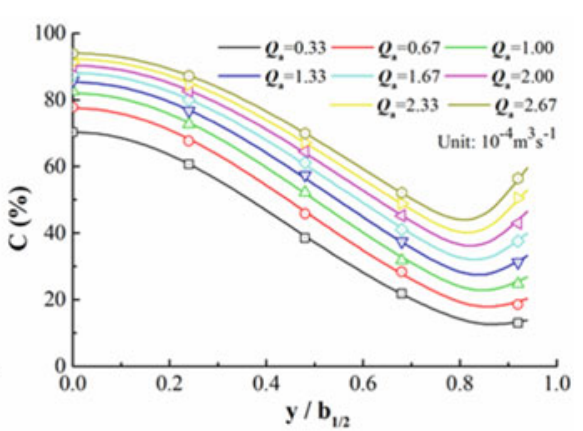

(c) $x / a=0.08$

Fig. 5.14 Distribution of the air concentration by aeration with an air vent (flow velocity: $1.19 \mathrm{~m} / \mathrm{s}$ ) 
of 6.4 million KW and a normal water level of $380 \mathrm{~m}$, Xiangjiaba has a guaranteed power output of 2.009 million KW, a mean annual energy production of 307.447 billion $\mathrm{KW} \cdot \mathrm{H}$, and 5125 annual installed utilization hours.

The key structures include the dam, the powerhouse at the dam toe on the left bank, the ship lift on the left bank, the flood discharge dam section, the underground powerhouse on right bank, powerhouses at the dam toe on both banks, and irrigation water intake on both banks. The structures for flood discharge and energy dissipation of Xiangjiaba are adjacent to Shuifu County and the Yunnan Natural Gas Chemical Plant, a large enterprise. Because the dam site has special environmental requirements, ski-jump energy dissipation, which has a relatively severe atomization impact, cannot be used. For this reason, underflow energy dissipation was adopted in the preliminary design. However, due to the high hydraulic head and large flow rate per unit width, the near-bottom flow velocity of the stilling basin reached more than $40 \mathrm{~m} / \mathrm{s}$, severely threatening the safety of the flood discharge. Considering both the technical characteristics of the project and the requirements of flood discharge and energy dissipation, the State Key Laboratory of Hydraulics and Mountain River Engineering, Sichuan University, proposed a new form of energy dissipation using multilevel multihorizontal submerged jets. The flood discharge structure adopts six surface outlets and five intermediate outlets. For the surface outlets, an open overflow weir is adopted with a crest elevation of $354.0 \mathrm{~m}$, the discharge chute is $8 \mathrm{~m}$ wide and is connected to the horizontal section after the ogee section, and the floor of the exit has an elevation of $261.0 \mathrm{~m}$. For the intermediate outlets, the discharge chute has a width of $6 \mathrm{~m}$, the floor of the entrance has an elevation of $305.0 \mathrm{~m}$, the outlet has a size of $6.0 \times 9.6 \mathrm{~m}$ (width $\times$ height), the outlet section is still horizontal (no depression angle), and the floor of the exit has an elevation of $253.0 \mathrm{~m}$. The flood discharge section of the dam has a length of $132 \mathrm{~m}$, the stilling basin has a width of $108 \mathrm{~m}$, a length of $228 \mathrm{~m}$, a basin floor elevation of $245.0 \mathrm{~m}$, a tail bucket elevation of $270 \mathrm{~m}$, and sidewall crest elevation of $296.0 \mathrm{~m}$ on both sides.

\subsubsection{Characteristics of the Flood Discharge and Energy Dissipation}

In the stilling basin with multilevel multihorizontal submerged jets, energy is dissipated by generating swirling and strong turbulence through the hydraulic jump (Fig. 5.15). In addition, because the high-velocity mainstream is always far from the floor, the near-bottom flow velocity of the stilling basin can be significantly reduced. Tests showed that the near-bottom flow velocity of the stilling basin had a maximum positive value in the range of $15.84-17.81 \mathrm{~m} / \mathrm{s}$ and a maximum negative value in the range of -10.48 to $-13.02 \mathrm{~m} / \mathrm{s}$, much lower than the near-bottom flow velocity of conventional underflow, which is greater than $40 \mathrm{~m} / \mathrm{s}$, so erosion damage to the floor of the stilling basin can be avoided. The maximum positive flow velocity occurred on the floor of the stilling basin with a maximum distance 

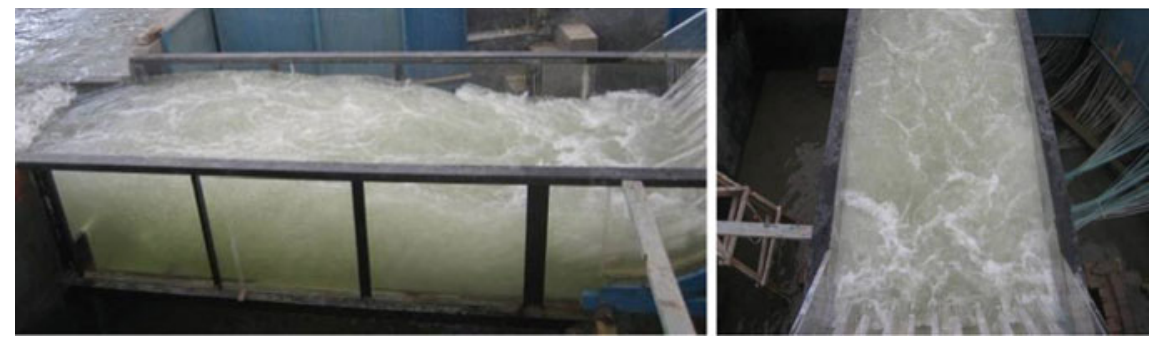

Fig. 5.15 Water flow regime in the stilling basin with multihorizontal submerged jets

of $64 \mathrm{~m}$ and a minimum distance of $52 \mathrm{~m}$ from the step-down floor of the stilling basin. The maximum negative flow velocity occurred on the floor of the stilling basin with a maximum distance of $20 \mathrm{~m}$ and a minimum distance of $12 \mathrm{~m}$ from the step-down floor of the stilling basin. The jet flow velocity attenuated rapidly in the range of 0-100 $\mathrm{m}$ from the step-down floor, beyond which the velocity diffused uniformly in the water depth direction. When the surface and intermediate outlets were combined for flood discharge, the length of the recirculation zone under the jets increased, and the corresponding flow velocity increased slightly. The range of the downstream swirling varies with different types of step-down floors, the position of the mainstream reaching the floor of the stilling basin moves between the upstream and downstream, and the near-bottom flow velocity at the fixed measuring point near the impinging zone varies between positive and negative.

In engineering design, the vertical vortex problem has received much attention. However, as discussed in Sect. 5.3 of this chapter, under the turbulence of the jet itself and the interference of transverse vortices, although the vertical vortices formed by multihorizontal jets could intermittently reach the floor of the stilling basin, there was no continuous penetration of vertical vortices and hence no cavitation erosion damage to the floor of the stilling basin. Thus, the stilling basin has been operated safely since the project was completed.

\subsection{Conclusions}

The following main conclusions can be drawn based on the analysis in this chapter:

(1) Strong shear is the main form of jet energy dissipation. Therefore, the range of the zone of energy dissipation by shear should be maximized in the skijump energy dissipation of high-head dam projects to reduce the impingement intensity of the impact energy dissipation zone.

(2) Under the turbulence of the jets themselves and the interference of the transverse vortices, although the vertical vortices formed by multihorizontal jets can 
intermittently reach the floor of the stilling basin, there is no continuous penetration of vertical vortices and thus no cavitation erosion damage to the floor of the stilling basin.

(3) There is a high risk of cavitation in the vortex area of the pressure flow after the sudden contraction of the flow area. Decompression model tests are needed in engineering design to assess the risk of cavitation. When cavitation is unavoidable, one can consider the use of vent aeration to reduce or eliminate cavitation erosion damage.

\section{References}

Arndt, R. E., Ellis, C., \& Paul, S. (1995). Preliminary investigation of the use of air injection to mitigate cavitation erosion.

Barata, J. M., Durao, D., Heitor, M., \& McGuirk, J. (1991). Impingement of single and twin turbulent jets through a crossflow. AIAA Journal, 29(4), 595-602.

Bollaert, E., \& Schleiss, A. (2003). Scour of rock due to the impact of plunging high velocity jets Part I: A state-of-the-art review. Journal of Hydraulic Research, 41(5), 451-464.

Chen, I. Y., Liu, C. C., Chien, K. H., \& Wang, C. C. (2007). Two-phase flow characteristics across sudden expansion in small rectangular channels. Experimental Thermal \& Fluid Science, 32(2), 696-706.

Chen, J.-G., Zhang, J.-M., Xu, W.-L., Li, S., \& He, X.-L. (2013). Particle image velocimetry measurements of vortex structures in stilling basin of multi-horizontal submerged jets. Journal of Hydrodynamics, 25(4), 556-563.

Chen, J.-G., Zhang, J.-M., Xu, W.-L., \& Wang, Y.-R. (2010). Numerical simulation of the energy dissipation characteristics in stilling basin of multi-horizontal submerged jets. Journal of Hydrodynamics, 22(5), 732-741.

Chen, J. G., Zhang, J. M., Xu, W. L., \& Peng, Y. (2014). Characteristics of the velocity distribution in a hydraulic jump stilling basin with five parallel offset jets in a twin-layer configuration. Journal of Hydraulic Engineering, 140(2), 208-217.

Chen, Y., Tseng, C.-Y., Lin, Y.-T., \& Wang, C.-C. (2009). Two-phase flow pressure change subject to sudden contraction in small rectangular channels. International Journal of Multiphase Flow, 35(3), 297-306.

Deng, J., Xu, W. L., Zhang, J. M., Qu, J. X., \& Yang, Y. Q. (2008). A new type of plunge poolMulti-horizontal submerged jets. Science in China, 51(12), 2128-2141.

Durrett, R., Stevenson, W., \& Thompson, H. (1988). Radial and axial turbulent flow measurements with an LDV in an axisymmetric sudden expansion air flow.

Ervine, D., \& Falvey, H. (1987). Behaviour of turbulent water jets in the atmosphere and in plunge pools. Proceedings of the Institution of Civil Engineers, 83(1), 295-314.

Fiorotto, V., \& Rinaldo, A. (1992). Fluctuating uplift and lining design in spillway stilling basins. Journal of Hydraulic Engineering, 118(4), 578-596.

Guo, W. S., Li, L. G., Liu, C., \& Li, N. W. (2017). Study on the flow field of a submerged jet. Advanced Engineering Sciences, 49(S1), 35-43.

Jia, J. (2016). A technical review of hydro-project development in China. Engineering, 3, 302-312.

Li, R., Xu, W.-L., Luo, J., Yuan, H., \& Zhao, W.-Y. (2019). A study on aeration to alleviate cavitation erosion in the contraction section of pressure flow. Journal of Fluids Engineering, 141(9).

Liu, C., Li, L. G., \& Li, N. W. (2015). Research on instantaneous flow characteristics of the falling submerged jet in a pool based on PIV technique. South to North Water Transfers and Water Science \& Technology, 13(3), 471-475. 
Manso, P., Bollaert, E., \& Schleiss, A. (2007). Impact pressures of turbulent high-velocity jets plunging in pools with flat bottom. Experiments in Fluids, 42(1), 49-60.

Ohtsu, I., Yasuda, Y., \& Ishikawa, M. (1999). Submerged hydraulic jumps below abrupt expansions. Journal of Hydraulic Engineering, 125(5), 492-499.

Roul, M. K., \& Dash, S. K. (2011). Two-phase pressure drop caused by sudden flow area contraction/expansion in small circular pipes. International Journal for Numerical Methods in Fluids, 66(11), 1420-1446.

Saripalli, K. (1987). Laser doppler velocimeter measurements in 3-D impinging twin-jet fountain flows. In Turbulent shear flows 5 (pp. 146-168). Berlin: Springer.

Tamura, Y., \& Matsumoto, Y. (2009). Improvement of bubble model for cavitating flow simulations. Journal of Hydrodynamics, 21(1), 41-46.

Wei-lin, X., Hua-sheng, L., Yong-quan, Y., \& Chi-gong, W. (1996). Numerical simulation of 3-D turbulent flows of plunge pool and energy dissipation analysis. Journal of Hydrodynamics, 5.

Wu, J. H., \& AI, W. Z. (2010). Flows trough energy dissipaters with sudden reduction and sudden enlargement forms. Journal of Hydrodynamics, 3, 70-75.

Zhong, T., Xu, W.-L., Wang, W., \& Liu, S. J. (2009). Hydraulic characteristics of plug energy dissipater in flood discharge tunnel. Journal of Hydrodynamics, 6, 73-80.

Open Access This chapter is licensed under the terms of the Creative Commons AttributionNonCommercial 4.0 International License (http://creativecommons.org/licenses/by-nc/4.0/), which permits any noncommercial use, sharing, adaptation, distribution and reproduction in any medium or format, as long as you give appropriate credit to the original author(s) and the source, provide a link to the Creative Commons license and indicate if changes were made.

The images or other third party material in this chapter are included in the chapter's Creative Commons license, unless indicated otherwise in a credit line to the material. If material is not included in the chapter's Creative Commons license and your intended use is not permitted by statutory regulation or exceeds the permitted use, you will need to obtain permission directly from the copyright holder. 